\title{
Urinary proteomics before and after extracorporeal circulation in patients with and without acute kidney injury
}

\author{
Fabienne Aregger, MD, ${ }^{\mathrm{a}, *}$ Christiane Pilop, $\mathrm{PhD},{ }^{\mathrm{a}, *}$ Dominik E. Uehlinger, MD, ${ }^{\mathrm{a}}$ René Brunisholz, PhD, \\ Thierry P. Carrel, MD, ${ }^{c}$ Felix J. Frey, MD, ${ }^{a}$ and Brigitte M. Frey, $\mathrm{PhD}^{\mathrm{a}}$
}

Objective: Acute kidney injury is a well-known complication with high morbidity and mortality after cardiopulmonary bypass. Cardiopulmonary bypass-associated acute kidney injury is still poorly understood.

\begin{abstract}
Methods: Thirty-six patients undergoing elective cardiopulmonary bypass were enrolled. Spot urine samples before and after cardiopulmonary bypass were collected. Acute kidney injury was defined according to the RIFLE classification. To identify differentially regulated proteins after cardiopulmonary bypass, we first analyzed the urinary proteome before and after cardiopulmonary bypass. To identify differentially regulated proteins in acute kidney injury, we next compared the urinary proteome obtained on the first postoperative day between patients with and without acute kidney injury. Difference fluorescence gel electrophoresis was used to compare protein profiles and mass spectrometry to identify individual proteins.
\end{abstract}

Results: After cardiopulmonary bypass, inflammation-associated (zinc-alpha-2-glycoprotein, leucine-rich alpha-2-glycoprotein, mannan-binding lectin serine protease 2, basement membrane-specific heparan sulfate proteoglycan, and immunoglobulin kappa) or tubular dysfunction-associated (retinol-binding protein, adrenomedullin-binding protein, and uromodulin) proteins were differentially regulated. Acute kidney injury developed in 6 of 36 patients. A modified urinary albumin was increased, and zinc-alpha-2-glycoprotein and a fragment of adrenomedullin-binding protein were decreased in patients with acute kidney injury. Decreased excretion of zinc-alpha2-glycoprotein in patients with acute kidney injury was confirmed by Western blot and enzyme-linked immunosorbent assay in an independent cohort of 22 patients with and 46 patients without acute kidney injury.

Conclusion: Cardiopulmonary bypass leads to increased urinary excretion of inflammatory proteins and markers of tubular injury. Zinc-alpha-2-glycoprotein is a potentially useful predictive marker for acute kidney injury after cardiopulmonary bypass surgery. (J Thorac Cardiovasc Surg 2010;139:692-700)

Acute kidney injury (AKI) is a well-known serious complication after cardiac surgery. The incidence of AKI is $5 \%$ to $30 \%$, depending on its definition. ${ }^{1}$ Mortality of patients with AKI requiring renal replacement therapy is as high as $80 \%{ }^{1}$ The precise mechanisms of AKI after cardiopulmonary bypass (CPB) are still debated. Possible contributors leading to acute tubular damage are ischemia-reperfusion injury, atheroembolism, hypothermia, and nephrotoxic agents. Several up-regulated proteins in urine have been identified after CPB, correlating with tubular damage, ${ }^{2}$ inflammation, ${ }^{3}$ or oxidative stress. ${ }^{4}$ Presently, AKI is typically diagnosed by measuring serum creatinine concentrations,

From the Department of Nephrology/Hypertension, ${ }^{a}$ Inselspital, University of Bern, Bern, Switzerland; Functional Genomics Center Zurich, ${ }^{\mathrm{b}}$ Zurich, Switzerland; and Cardiovascular Surgery, ${ }^{\mathrm{c}}$ Inselspital, University of Bern, Bern, Switzerland.

Grant support: Swiss National Foundation for Scientific Research Number 3100A0102153 to F.J.F. and B.M.F.

Disclosures: None.

*F.A. and C.P. contributed equally to the article.

Received for publication July 27, 2009; revisions received Oct 19, 2009; accepted for publication Nov 6, 2009.

Address for reprints: Brigitte M. Frey, PhD, Department of Nephrology/Hypertension, Freiburgstrasse 15, University Hospital of Bern, CH-3010 Bern, Switzerland (E-mail: brigitte.frey@dkf.unibe.ch).

$0022-5223 / \$ 36.00$

Copyright (c) 2010 by The American Association for Thoracic Surgery doi:10.1016/j.jtcvs.2009.11.015 a parameter without predictive value for acute changes in kidney function. Thus, prognostic biomarkers for AKI are needed.

The identification of patterns of urinary proteins for noninvasive diagnosis of renal diseases has a long history, ${ }^{5}$ with a recent revival because of advances in clinical proteomics allowing the discovery of novel biomarkers with potential clinical utility. ${ }^{2,6}$ Two-dimensional (2D) polyacrylamide gel electrophoresis, a promising tool in proteome research, allows the separation of complex mixtures of intact proteins at high resolution, differentiation of a variety of post-translationally modified isoforms, and determination of differentially expressed proteins. $^{7,8}$ Unlu and colleagues ${ }^{9}$ first described 2D fluorescence difference gel electrophoresis (DIGE), enabling the separation of more than 1 sample in a single 2D gel. The comparison of 2 protein samples on the same gel is a sensitive strategy for detecting and quantifying differences in the proteome before and after an intervention such as $\mathrm{CPB}$, as proposed in the present investigation. The use of an internal standard for normalization minimizes experimental variations, thus increasing confidence in matching and quantifying different spots from the same or different patients. ${ }^{10}$ The aim of the current study was to detect differential regulation in the urinary proteome before and after CPB using DIGE to analyze mechanisms 


$\begin{aligned} \text { Abbreviations and } & \text { Acronyms } \\ \text { 2D } & \text { 2-dimensional } \\ \text { AKI } & \text { acute kidney injury } \\ \text { AMBP } & \text { adrenomedullin-binding } \\ & \text { protein } \\ & =\text { area under the curve } \\ \text { AUC } & \text { cardiopulmonary bypass } \\ \text { CPB } & =\text { difference gel electrophoresis } \\ \text { DIGE } & \text { estimated glomerular filtration } \\ \text { eGFR } & \text { rate } \\ & \text { enzyme-linked } \\ & \text { immunosorbent assay } \\ \text { ELISA } & \text { glomerular filtration rate } \\ = & \text { heparan sulfate proteoglycan } \\ \text { GFR } & \text { matrix-assisted laser } \\ \text { HSPG } & \text { desorption ionization time-of- } \\ \text { MALDI-MS } & \text { flight mass spectrometry } \\ \text { MALDI-MS/MS }= & \text { matrix-assisted laser } \\ & \text { desorption ionization time-of- } \\ & \text { flight mass spectrometry/mass } \\ & \text { spectrometry } \\ = & \text { neutrophil gelatinase- } \\ & \text { associated lipocalin } \\ = & \text { retinol-binding protein } \\ \text { NGAL } & \text { surface-enhanced laser } \\ \text { RBP } & \text { desorption/ionization time-of- } \\ \text { SELDI-TOF-MS } & \text { flight mass spectrometry } \\ = & \text { systemic inflammatory } \\ & \text { response syndrome } \\ = & \text { zinc-alpha-2-glycoprotein } \\ \text { SIRS } & \end{aligned}$

involved in AKI after CPB. Because early biomarkers for AKI are lacking, we analyzed the postoperative urinary proteome in patients with and without AKI.

\section{MATERIALS AND METHODS}

\section{Subjects and Sample Collection}

Written informed consent was obtained from all patients, according to local ethics committee approval. Patients aged more than 18 years who underwent elective CPB between January 2006 and May 2006 were enrolled prospectively. Exclusion criteria included proteinuria greater than $1 \mathrm{~g} / 24$ hours, microhematuria ( $\geq 5$ erythrocytes per high power field), estimated glomerular filtration rate (eGFR) less than $40 \mathrm{~mL} / \mathrm{min}$, use of radio contrast media or nonsteroidal anti-inflammatory drugs in the previous 10 days, and need for urgent surgery. In case of the DIGE analysis group (A), first morning urine samples were collected from 36 patients on the day of operation and the first postoperative day. Urine was immediately centrifuged at $1000 \mathrm{rpm}$ for 5 minutes. The supernatant was filtered through a $0.22 \mu \mathrm{m}$ filter unit (Millipore, Bedford, Mass) and stored at $-70{ }^{\circ} \mathrm{C}$ until further analysis according to the suggestion of Thongboonkerd. ${ }^{11}$ For a second group (111 patients), which was not analyzed by DIGE (validation group B), urine was collected only on the first postoperative day.

\section{Surgical Procedure and Serial Analysis of Renal Function}

Surgery was performed according to standard local practice, and CPB was conducted in moderate hypothermia $\left(32{ }^{\circ} \mathrm{C}-34{ }^{\circ} \mathrm{C}\right)$. All patients received antifibrinolytic drugs to decrease postoperative blood loss (aprotinin in all 36 patients in group A; tranexamic acid [Cyklokapron; Pfizer US Pharmaceuticals, New York, NY] in all 111 patients in group B). Routine serum creatinine concentrations were measured daily for the first 3 days and afterward according to standard local practice until discharge (Creatinine Plus; Roche Diagnostics, West Sussex, UK). Urine dipstick measurements (Arkray Aution, ARKRAY Inc, Kyoto, Japan) were performed in all samples.

\section{Protein Preparation for Difference Gel Electrophoresis}

Samples thawed on ice were precipitated according to the method of Bensadoun and Weinstein ${ }^{12}$ with slight modifications. Briefly, $200 \mu \mathrm{L}$ of $2 \%$ sodium deoxycholate (Sigma-Aldrich, St Louis, Mo) were added to $20 \mathrm{~mL}$ of urine. After incubation on ice for 30 minutes, trichloroacetic acid (Fluka AG, St Louis, Mo) was added to a final concentration of $10 \%$. Samples were then incubated overnight at $4{ }^{\circ} \mathrm{C}$ and centrifuged at $14,000 \mathrm{rcf}$ for 1 hour. The supernatant was discarded and the pellet was washed twice with $90 \%$ acetone, followed by resuspension of the pellet in DIGE buffer according to the manufacturer's instructions (GE Healthcare, Buckinghamshire, UK). Protein concentrations were measured according to the Bradford method. ${ }^{13}$

\section{Study Design and 2-Dimensional Electrophoresis}

AKI was defined according to the RIFLE classification. ${ }^{14}$ Three degrees of kidney dysfunction were assigned as Risk (increase of serum creatinine $>$ $50 \%$ or GFR decrease $>25 \%$ or oliguria), Injury (increase of serum creatinine $>100 \%$ or GFR decrease $>50 \%$ or oliguria), and Failure (increase in serum creatinine $>200 \%$ or GFR decrease $>75 \%$ or serum creatinine $>4$ $\mathrm{mg} / \mathrm{dL}$ or oliguria). Because of incomplete data of urinary output quantification, we did not include the criteria of oliguria for classification. eGFR was calculated with the simplified Modification of Diet in Renal Disease formula using serum creatinine, age, race, and gender. The study design is given in Figure 1. For each of the 6 patients in whom AKI developed, 1 patient from the other 30 patients who did not develop AKI was selected as a match. Gender and age were used as matching criteria.

To compare preoperative with postoperative urinary proteome, 12 DIGE gels were run simultaneously from 6 patients undergoing $\mathrm{CPB}$ with AKI and 6 patients undergoing $\mathrm{CPB}$ without AKI. Urinary proteins $(50 \mu \mathrm{g})$ were labeled with CyDye DIGE Fluor minimal dye. Cy3Dye was used for labeling the protein samples before $\mathrm{CPB}$ and $\mathrm{Cy} 5 \mathrm{Dye}$ after $\mathrm{CPB}$. To guarantee uniform distribution, the labeling was inverted in half of the patients. Cy2Dye labeling was used for the internal standardization. For this purpose, $50 \mu \mathrm{g}$ of a mixture of all samples investigated on a given run were analyzed. After labeling proteins of each patient (sample before and after CPB plus internal standard), samples were pooled and loaded onto an IPG dry strip pH 3-11 (GE Healthcare).

To compare the postoperative urinary proteome between patients with and without AKI, urinary proteins were labeled with Cy3Dye in patients with AKI and Cy5Dye in patients without AKI and vice versa. Six gels were run, each including a sample of a patient with AKI, a patient without $\mathrm{AKI}$, and the internal standard, and further analyzed as described below.

After isoelectric focusing (total $73 \mathrm{kVh}$ ), the IPG strip was equilibrated in dithiothreitol buffer and iodoacetamide buffer for 15 minutes sequentially. The second dimension was conducted with a $13 \%$ sodium dodecyl sulfate-polyacrylamide gel electrophoresis for 6 hours.

\section{Gel Image Analysis}

Labeled proteins were visualized using a Typhoon 9400 imager (GE Healthcare). Spot matching, quantification, and statistical analyses were performed using Proteomweaver software (Definiens AG, Munich, 


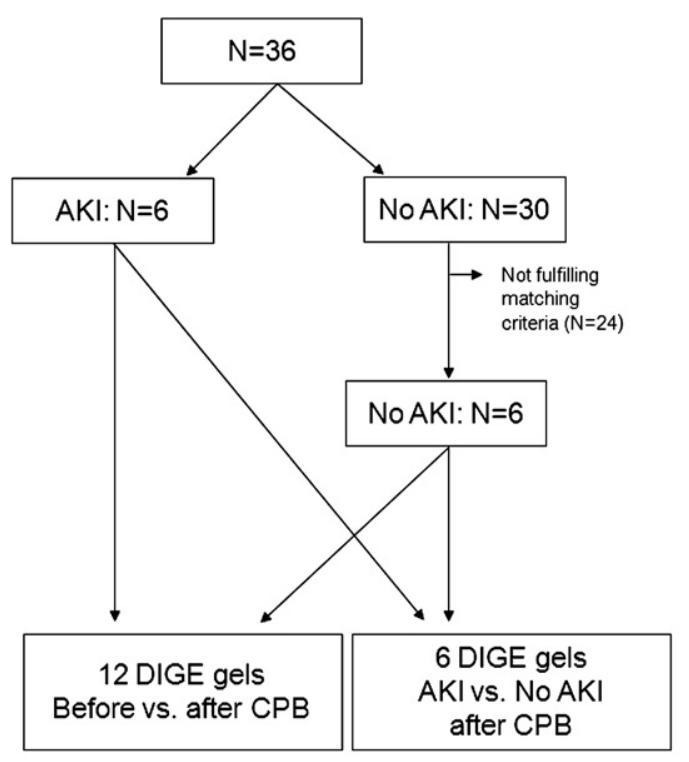

A

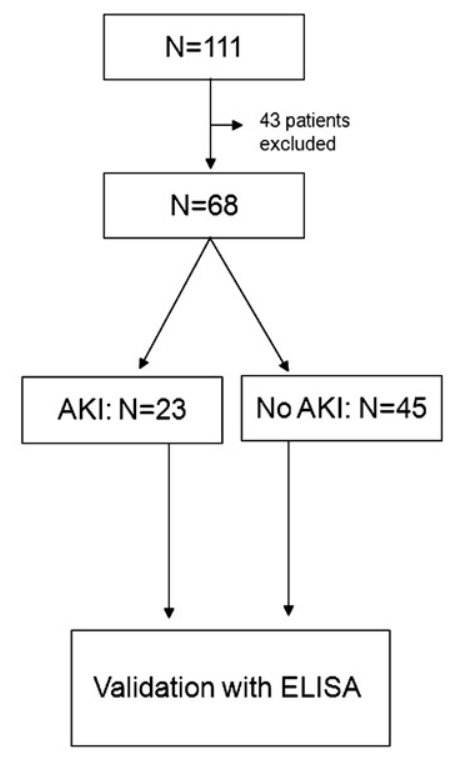

B

FIGURE 1. Patient selection and study design. Forty-three patients were excluded in group B for the following reasons: contrast media in the previous 10 days $(\mathrm{N}=19)$, emergency procedure $(\mathrm{N}=13)$, eGFR $<40 \mathrm{~mL} / \mathrm{min}(\mathrm{N}=10)$, and proteinuria $>1 \mathrm{~g} / \mathrm{d}(\mathrm{N}=1)$. AKI, Acute kidney injury; $C P B$, cardiopulmonary bypass; DIGE, difference fluorescence gel electrophoresis; ELISA, enzyme-linked immunosorbent assay.

Germany) as previously described. ${ }^{8}$ Protein spots were considered to be significantly differentially regulated when the $P$ value was less than .05 and the regulation factor was greater than 2 .

\section{Protein Identification}

For identification of differential regulated proteins, individual spots were cut from the gel and trypsin digested. Extracted peptides were analyzed by matrix-assisted laser desorption ionization time-of-flight mass spectrometry (MALDI-MS) and matrix-assisted laser desorption ionization time-of-flight mass spectrometry/mass spectrometry (MALDI-MS/MS). ${ }^{8}$

\section{Validation}

Western blot technology was used to analyze reproducibility of the results derived from DIGE in the same sample set. ZAG was chosen for validation because it was the only full-length protein identified differentially regulated in patients with AKI. Therefore, $5 \mu \mathrm{g}$ of urine protein were loaded onto a $12 \%$ sodium dodecyl sulfate-polyacrylamide gel and separated by electrophoresis. Proteins were electroblotted onto polyvinylidene fluoride membrane (GE Healthcare). Rabbit antibody against ZAG (1:5000, Santa Cruz Biotechnology, Santa Cruz, Calif) was used. The intensity of Western blot bands were quantified with ImageJ.

Because the finding by DIGE was reproducible by Western blot, an independent group of 68 patients were analyzed for validation (group B). In these patients, urinary ZAG was determined by enzyme-linked immunosorbent assay (ELISA) (BioVendor, Brno, Czech Republic) according to the manufacturer's instruction. For validation, investigators were blinded to the patients' outcome. ZAG excretion was normalized with the total protein excretion.

\section{Statistical Analysis}

Values are given as mean \pm standard deviation, or median and range. Nonparametic tests (Mann-Whitney) were performed. Chi-square analysis and Fisher exact tests were considered for discrete data. Correlation analysis was performed using Spearman's coefficient of rank correlation. Bonferroni correction was applied to the clinical data to correct for multiple testing. Receiver operating characteristics were generated, and the area under the curve (AUC) was calculated with GraphPad Prism v.5.01.

\section{RESULTS \\ Clinical Data}

Clinical data of groups A and B are summarized in Table 1. Of the 111 patients considered for validation (Figure 1), 43 were excluded for the following reasons: contrast media in the previous 10 days $(\mathrm{N}=19)$, emergency procedure $(\mathrm{N}=$ 13), eGFR less than $40 \mathrm{~mL} / \mathrm{min}(\mathrm{N}=10)$, and proteinuria more than $1 \mathrm{~g} / \mathrm{d}(\mathrm{N}=1)$, resulting in 68 patients eligible for validation. AKI, according to the RIFLE classification, occurred in $17 \%$ in group A and in $34 \%$ in group B. In group $\mathrm{A}, 3$ patients had risk and 3 patients had injury. ${ }^{14}$ In group B, 18 patients had risk, 3 patients had injury, and 2 patients had failure. One patient in group B had to be dialyzed, and 1 patient with AKI died. The mean time to reach maximal creatinine was $4.33 \pm 1.4$ days in group $\mathrm{A}$ and $3.4 \pm 1.1$ days in group B. Patients with AKI were more frequently female, more frequently developed atrial fibrillation, and had longer hospitalizations and lower postoperative renal function (Table 1, group B).

\section{Protein Pattern Before and After Cardiopulmonary Bypass}

Urine samples of the 6 patients with AKI and the 6 matched patients without AKI were analyzed before and after CPB using DIGE. Each gel contained the urinary proteome before and after $\mathrm{CPB}$, as well as the internal standard (Figure 2, $A-C$ ). All differentially regulated proteins that could be visualized by Coomassie staining were picked. Twenty-five differentially regulated spots could be identified by MALDI-MS and MALDI-MS/MS; they corresponded to 10 proteins (Figure 2, D; Table 2). 
TABLE 1. Characteristics of study population

\begin{tabular}{|c|c|c|c|c|c|c|}
\hline \multirow[b]{3}{*}{ No. of patients } & \multicolumn{3}{|c|}{ Group A } & \multicolumn{3}{|c|}{ Group B } \\
\hline & AKI & No AKI & $\boldsymbol{P}$ & AKI & No AKI & $\boldsymbol{P}$ \\
\hline & 6 & 6 & & 23 & 45 & \\
\hline \multicolumn{7}{|l|}{ Baseline } \\
\hline Age, y $($ mean \pm SD) & $72 \pm 7$ & $68 \pm 8$ & NS & $70 \pm 11$ & $63 \pm 11$ & NS \\
\hline Female, $\mathrm{n}(\%)$ & $2(33)$ & $2(33)$ & NS & $15(65)$ & $7(16)$ & $<.001$ \\
\hline Hypertension, n (\%) & $4(67)$ & $5(83)$ & NS & $16(70)$ & $23(51)$ & NS \\
\hline Diabetes, $\mathrm{n}(\%)$ & $0(0)$ & $2(33)$ & NS & $4(17)$ & $10(22)$ & NS \\
\hline Creatinine $\mu \mathrm{mol} / \mathrm{L}($ mean $\pm \mathrm{SD})$ & $84 \pm 13$ & $78 \pm 11$ & NS & $79 \pm 17$ & $78 \pm 11$ & NS \\
\hline eGFR mL/min (mean $\pm \mathrm{SD})$ & $71 \pm 10$ & $80 \pm 12$ & NS & $74 \pm 20$ & $86 \pm 13$ & NS \\
\hline eGFR < 60 mL/min, $\mathrm{n}(\%)$ & $1(17)$ & $1(17)$ & NS & $5(22)$ & $0(0)$ & NS \\
\hline \multicolumn{7}{|l|}{ Outcome } \\
\hline \multicolumn{7}{|l|}{ Surgery } \\
\hline CABG, n (\%) & $5(83)$ & $5(83)$ & NS & $7(30)$ & $29(64)$ & NS \\
\hline Valve, n (\%) & $0(0)$ & $0(0)$ & NS & $12(52)$ & $9(20)$ & NS \\
\hline Combined, n (\%) & $1(17)$ & $1(17)$ & NS & $4(17)$ & $7(16)$ & NS \\
\hline Time on ECC $(\min )($ mean \pm SD $)$ & $80 \pm 26$ & $99 \pm 36$ & NS & $91 \pm 40$ & $80 \pm 32$ & NS \\
\hline $\mathrm{ACT}(\min )($ mean $\pm \mathrm{SD})$ & $59 \pm 25$ & $56 \pm 16$ & NS & $63 \pm 27$ & $55 \pm 27$ & NS \\
\hline $\begin{array}{l}\text { Maximum serum } \\
\quad \text { creatinine } \mu \mathrm{mol} / \mathrm{L}(\text { mean } \pm \mathrm{SD})\end{array}$ & $153 \pm 38$ & $84 \pm 12$ & NS & $138 \pm 78$ & $83 \pm 13$ & $<.001$ \\
\hline Minimal eGFR $\mathrm{mL} / \mathrm{min}($ mean $\pm \mathrm{SD})$ & $37 \pm 9$ & $73 \pm 11$ & $<.003$ & $46 \pm 20$ & $80 \pm 14$ & $<.001$ \\
\hline Decrease in eGFR, \% (mean $\pm \mathrm{SD})$ & $47 \pm 12$ & $9 \pm 7$ & $<.003$ & $39 \pm 16$ & $4 \pm 12$ & $<.001$ \\
\hline $\begin{array}{l}\text { Red blood } \\
\quad \text { cell units, } \mathrm{n}(\text { mean } \pm \mathrm{SD})\end{array}$ & $2.7 \pm 2.3$ & $1.0 \pm 0.9$ & NS & $4.2 \pm 5.0$ & $2.0 \pm 1.8$ & NS \\
\hline Infection, n (\%) & $0(0)$ & $0(0)$ & NS & $2(9)$ & $2(4)$ & NS \\
\hline Atrial fibrillation, n (\%) & $3(50)$ & $3(50)$ & NS & $14(61)$ & $8(18)$ & $<.001$ \\
\hline Days of hospitalization, median (range) & $11(10-14)$ & $12(7-12)$ & NS & $13(9-48)$ & $10(6-38)$ & $<.001$ \\
\hline
\end{tabular}

Up-regulated proteins were zinc-alpha-2-glycoprotein (ZAG), adrenomedullin-binding protein (AMBP), immunoglobulin kappa (immunoglobulin kappa variable 1-5 protein), leucine-rich alpha-2-glycoprotein, gelsolin, carbonic anhydrase-1, plasma retinol-binding protein (RBP), mannan-binding lectin serine protease 2 , and basement membrane-specific heparan sulfate proteoglycan (HSPG). The 2 down-regulated spots were identified as uromodulin. Whereas all of the spots represented the entire protein, HSPG only appeared as its fragment, named "endorepellin.",

\section{Differently Regulated Proteins in Patients With Acute Kidney Injury}

To identify proteins regulated differently in patients with AKI after CPB, we analyzed the urinary proteome of 6 patients with AKI and 6 patients without AKI. Four differentially regulated proteins in patients with AKI could be identified as ZAG, AMBP, and serum albumin. AMBP appeared as its fragment and was together with ZAG downregulated in AKI urine. The only up-regulated protein spot was a modified albumin (Figure 2, $H$; Table 3 ). We decided to further validate the nonmodified and nonfragmented protein ZAG by Western blot and ELISA.

\section{Validation of Zinc-Alpha-2-Glycoprotein}

There was a significant correlation of the results from DIGE analysis and Western blot for urinary ZAG in the 12 patients analyzed (Figure 3,B). For validation of the differences observed by DIGE in these patients, a cohort of 68 patients (22 with AKI and 46 without AKI) were analyzed. Median ZAG excretion was lower in subjects with AKI (0.029; range, 0.009-0.106) than those without AKI (0.056; range, 0.008-0.32; $P<.02$; Figure 3, $C$ ).

Furthermore, there was a significant association of urinary ZAG with minimal postoperative eGFR compared with baseline $(r=0.32, P<.01$; Figure $3, D)$. Receiver operating characteristics of the 68 patients revealed an AUC of 0.68 for ZAG $(0.55-0.81, P<.02)$. In the subgroup analysis of the 5 patients with severe AKI ( 3 with injury and 2 with failure) compared with all 45 patients without AKI, the AUC was 0.80 for ZAG $(0.61-0.98, P<.05)$.

\section{DISCUSSION}

The present investigation analyzed the urinary proteome in a highly selected and well-defined population of subjects before and after CPB and compared the first postoperative urinary proteome between patients in whom AKI later did 

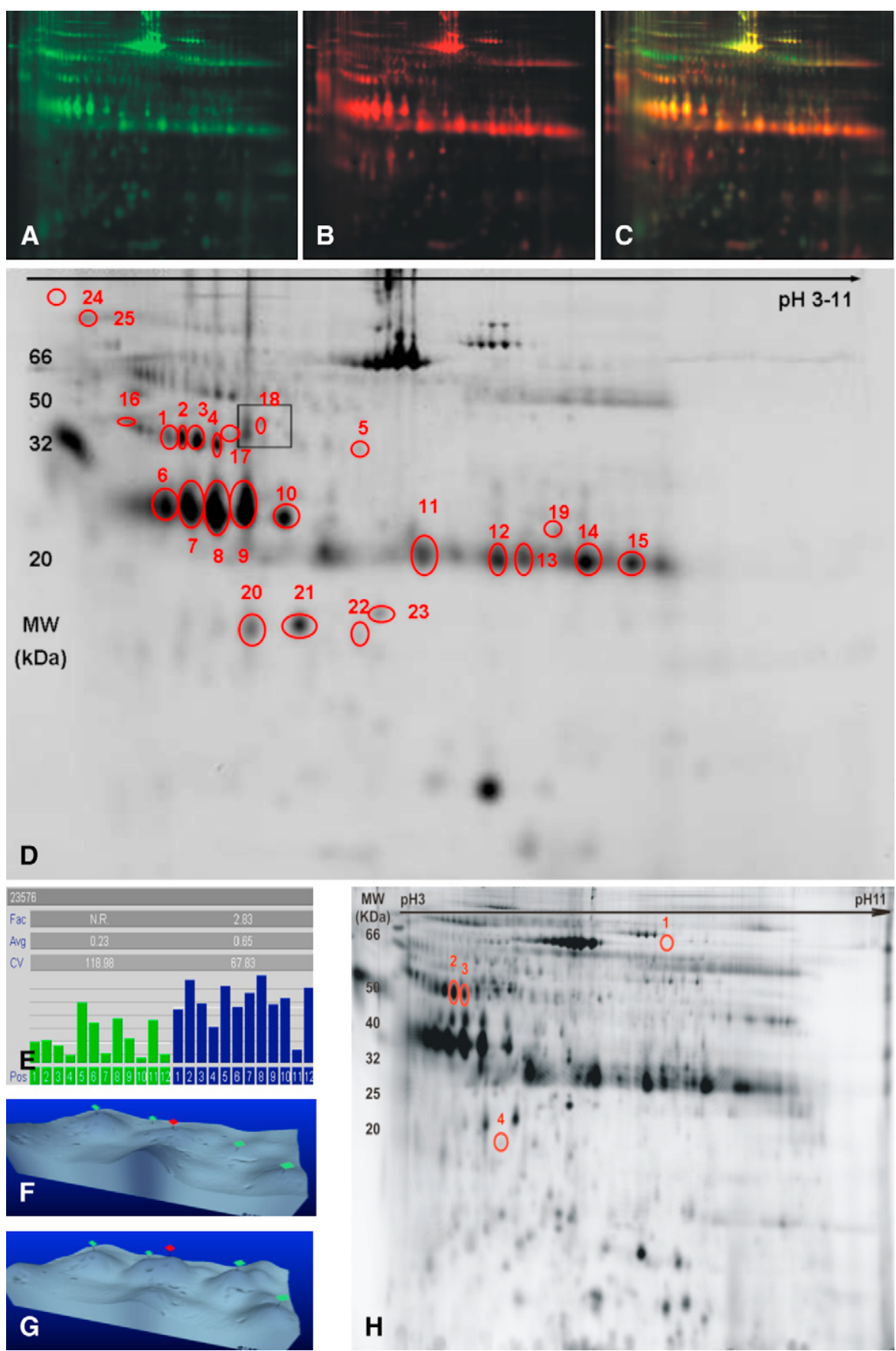

FIGURE 2. Representative example of 2D-DIGE gels. A, Cy3-labeled proteins ( $50 \mu \mathrm{g})$ of urine before CPB. B, Cy5-labeled proteins (50 $\mu \mathrm{g})$ of the same patient after CPB. C, color overlay of scanned gel images of urine proteins before CPB labeled with Cy3 and after CPB labeled with Cy5. D, 2D map of Cy2labeled proteins showing the location of significantly regulated and identified protein spots with a numbering system used as in Table 2. E, Comparison of spot 18 intensity among all patients in DIGE experiment (position 1-12); green bars represent the intensity before CPB and blue bars represent the intensity after CPB. F, G, Three-dimensional image of gelsolin protein spot (spot no. 18 or boxed area in D) before and after CPB. H, Differentially regulated protein spots in postoperative urine samples from patients with or without AKI. Highlighted spots in the 2D map represent significantly regulated and identified protein spots; the numbering system is that used in Table 3 .

or did not develop. We identified 10 differentially regulated proteins excreted in urine after $\mathrm{CPB}$ and obtained evidence that ZAG might be a useful predictive markers for AKI after CPB surgery.
The changes in the rate of urinary excretion of a defined protein as shown in the present investigation can be due to an increased production rate or an abnormal renal handling. The present study was unable to distinguish between these 
TABLE 2. Changes and identifications of urinary proteins after extracorporeal circulation

\begin{tabular}{|c|c|c|c|c|c|c|c|c|}
\hline & & Accession & Fold change in & Theoretic & MASCOT & $\begin{array}{c}\text { No. of } \\
\text { matching }\end{array}$ & Sequence & $\begin{array}{l}\text { No. of } \\
\text { matching }\end{array}$ \\
\hline Spot no.* & Protein & no. & intensity & $\mathbf{M r} / \mathbf{p I} \dagger$ & score $\ddagger$ & peptides & coverage $(\%)$ & MS/MS \\
\hline 1 & Zinc-alpha-2-glycoprotein & P25311 & (+) 3.14 & $33.8 / 5.6$ & 94 & 6 & 25.8 & 2 \\
\hline 2 & Zinc-alpha-2-glycoprotein & P25311 & (+) 3.31 & $33.8 / 5.6$ & 177 & 12 & 38.3 & 2 \\
\hline 3 & Zinc-alpha-2-glycoprotein & P25311 & (+) 3.80 & $33.8 / 5.6$ & 184 & 13 & 38.6 & 2 \\
\hline 4 & Zinc-alpha-2-glycoprotein & P25311 & (†) 2.88 & $33.8 / 5.6$ & 127 & 8 & 21.0 & 2 \\
\hline 5 & Zinc-alpha-2-glycoprotein & P25311 & (†) 2.08 & $33.8 / 5.6$ & 113 & 9 & 30.8 & 2 \\
\hline 6 & Adrenomedullin-binding protein & P02760 & (†) 2.92 & $39.0 / 5.8$ & 59 & 6 & 20.2 & 1 \\
\hline 7 & Adrenomedullin-binding protein & P02760 & (†) 3.51 & $39.0 / 5.8$ & 116 & 3 & 9.7 & 3 \\
\hline 8 & Adrenomedullin-binding protein & P02760 & (+) 3.37 & $39.0 / 5.8$ & 151 & 7 & 20.2 & 2 \\
\hline 9 & Adrenomedullin-binding protein & P02760 & (†) 3.51 & $39.0 / 5.8$ & 218 & 8 & 15.6 & 3 \\
\hline 10 & Adrenomedullin-binding protein & P02760 & (+) 3.92 & $39.0 / 5.8$ & 193 & 7 & 23.6 & 3 \\
\hline 11 & IGKV 1-5 protein & Q6GMW0 & (†) 2.00 & $25.7 / 5.8$ & 111 & 3 & 33.0 & 2 \\
\hline 12 & IGKV 1-5 protein & Q6GMW0 & (+) 2.22 & $25.7 / 5.8$ & 56 & 3 & 14.0 & 1 \\
\hline 13 & IGKV 1-5 protein & Q6PIH6 & (+) 2.30 & $26.2 / 6.3$ & 91 & 4 & 18.3 & 1 \\
\hline 14 & IGKV 1-5 protein & Q6GMW0 & (+) 2.67 & $25.7 / 5.8$ & 137 & 3 & 14.0 & 3 \\
\hline 15 & IGKV 1-5 protein & Q6GMW0 & (+) 2.99 & $25.7 / 5.8$ & 68 & 4 & 21.7 & 2 \\
\hline 16 & Leucine-rich alpha-2-glycoprotein & P02750 & (+) 3.35 & $38.2 / 5.7$ & 64 & 3 & 8.0 & 3 \\
\hline 17 & Gelsolin & Q5T0H7 & (†) 2.29 & $20.8 / 4.7$ & 59 & 3 & 10.1 & 1 \\
\hline 18 & Gelsolin & Q5T0H7 & (†) 2.83 & $20.8 / 4.7$ & 120 & 6 & 34.6 & 2 \\
\hline 19 & Carbonic anhydrase 1 & P00915 & (+) 3.60 & $28.7 / 6.6$ & 109 & 4 & 16.1 & 2 \\
\hline 20 & Plasma retinol-binding protein & P02753 & (†) 5.10 & $23.0 / 5.3$ & 88 & 5 & 18.9 & 2 \\
\hline 21 & Plasma retinol-binding protein & P02753 & (†) 5.57 & $23.0 / 5.3$ & 248 & 12 & 51.7 & 2 \\
\hline 22 & $\begin{array}{l}\text { Mannan-binding lectin } \\
\text { serine protease } 2\end{array}$ & O00187 & (†) 2.73 & $75.6 / 5.4$ & 122 & 4 & 5.7 & 4 \\
\hline 23 & Basement membrane-specific HSPG & P98160 & (+) 2.31 & $468.5 / 6.0$ & 659 & 18 & 5.8 & 9 \\
\hline 24 & Uromodulin & P07911 & (-) 2.44 & $69.7 / 5.0$ & 118 & 11 & 18.1 & 1 \\
\hline 25 & Uromodulin & P07911 & (-) 3.70 & $67.7 / 5.0$ & 117 & 11 & 18.1 & 1 \\
\hline
\end{tabular}

$M r / p I$, Molecular mass/isoelectric point; $M S / M S$, mass spectrometry/mass spectrometry; $H S P G$, heparan sulfate proteoglycan; $I G K V$, immunoglobulin kappa variable. *Spot number according to Figure 2, D. †Theoretic molecular mass and isoelectric point were calculated with the Compute pI/MW Tool from ExPASy (http://expasy.org/tools/pi_tool.html). $\ddagger$ MASCOT score $>61$ were significant $(P<.05)$ identifications.

2 mechanisms. Nevertheless, on the basis of the known physiology of these proteins and the disease state induced by $\mathrm{CPB}$, some reasonable speculations may be appropriate.

First, RBP and AMBP are well-known markers of proximal tubular dysfunction of various cause, ${ }^{15,16}$ including tubulopathy after cardiac surgery. ${ }^{3}$ These proteins are freely filtered by the glomerulus. A relevant mechanism of proximal tubular uptake of filtered proteins, including RBP, AMBP, immunoglobulin light chains, and albumin, is receptor-mediated endocytosis by megalin and cubilin. ${ }^{17}$ In rats with acute tubular injury induced by aristolochic acid and total body irradiation, proteinuria appeared on day 1 after the toxic event, followed by an impaired expression of megalin and cubilin on day $2 .^{18}$ The up-regulation of RBP, AMBP, immunoglobulin kappa variable 1-5, and albumin in urine after $\mathrm{CPB}$ observed is in line with an impaired megalin-mediated endocytosis. Thus, an impaired capacity of megalin for endocytosis seems to be an important and relevant mechanism of proteinuria after $\mathrm{CPB}$.

Second, ZAG, a glucocorticoid inducible plasma protein also known as "lipid-mobilizing factor," was up-regulated after $\mathrm{CPB}$ and down-regulated in patients with $\mathrm{AKI}$

TABLE 3. Comparison of urinary proteins between patients with and without acute kidney injury: Up-regulated ( $(+)$ and down-regulated (-) proteins in patients with acute kidney injury

\begin{tabular}{|c|c|c|c|c|c|c|c|c|}
\hline & & Accession & Fold change in & Theoretic & MASCOT & No. of matching & Sequence & No. of matching \\
\hline Spot No.* & Protein & No. & intensity & $\mathbf{M r} / \mathbf{p I} \dagger$ & score $\ddagger$ & peptides & coverage $(\%)$ & MS/MS \\
\hline 1 & Serum albumin & P02768 & (+) 4.46 & $66.5 / 5.7$ & 104 & 17 & 39.4 & 1 \\
\hline 2 & Zinc-alpha-2-glycoprotein & P25311 & (-) 2.00 & $32.1 / 5.7$ & 148 & 7 & 32.4 & 2 \\
\hline 3 & Zinc-alpha-2-glycoprotein & P25311 & (-) 2.04 & $32.1 / 5.7$ & 174 & 15 & 55.6 & 3 \\
\hline 4 & Adrenomedullin-binding protein & P02760 & (-) 2.56 & $39.0 / 5.8$ & 88 & 4 & 15.3 & 2 \\
\hline
\end{tabular}

$M r / p I$, Molecular mass/isoelectric point; $M S / M S$, mass spectrometry/mass spectrometry. ${ }^{*}$ Spot number according to Figure $2, H$. $\dagger$ Theoretic molecular mass and isoelectric point were calculated with the Compute pI/MW Tool from ExPASy (http://expasy.org/tools/pi_tool.html). $\ddagger$ MASCOT scores $>61$ were significant $(P<.05)$ identifications. 


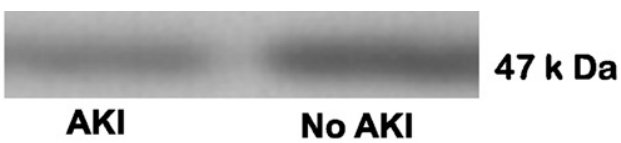

A

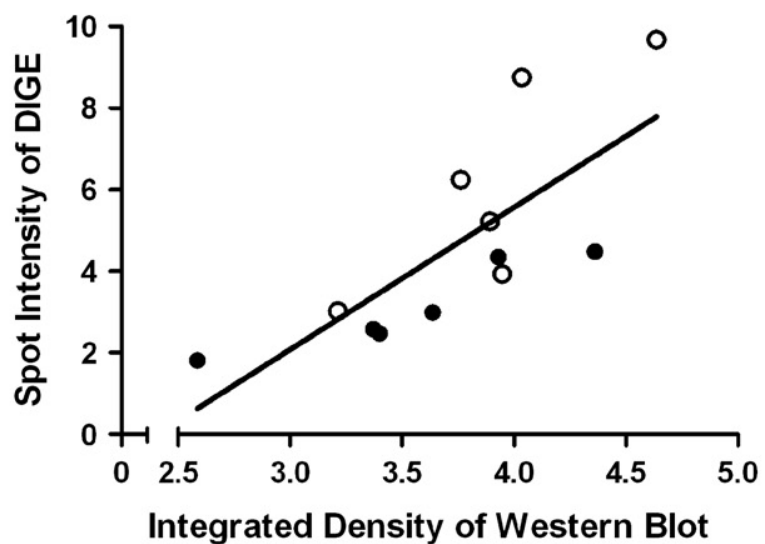

B
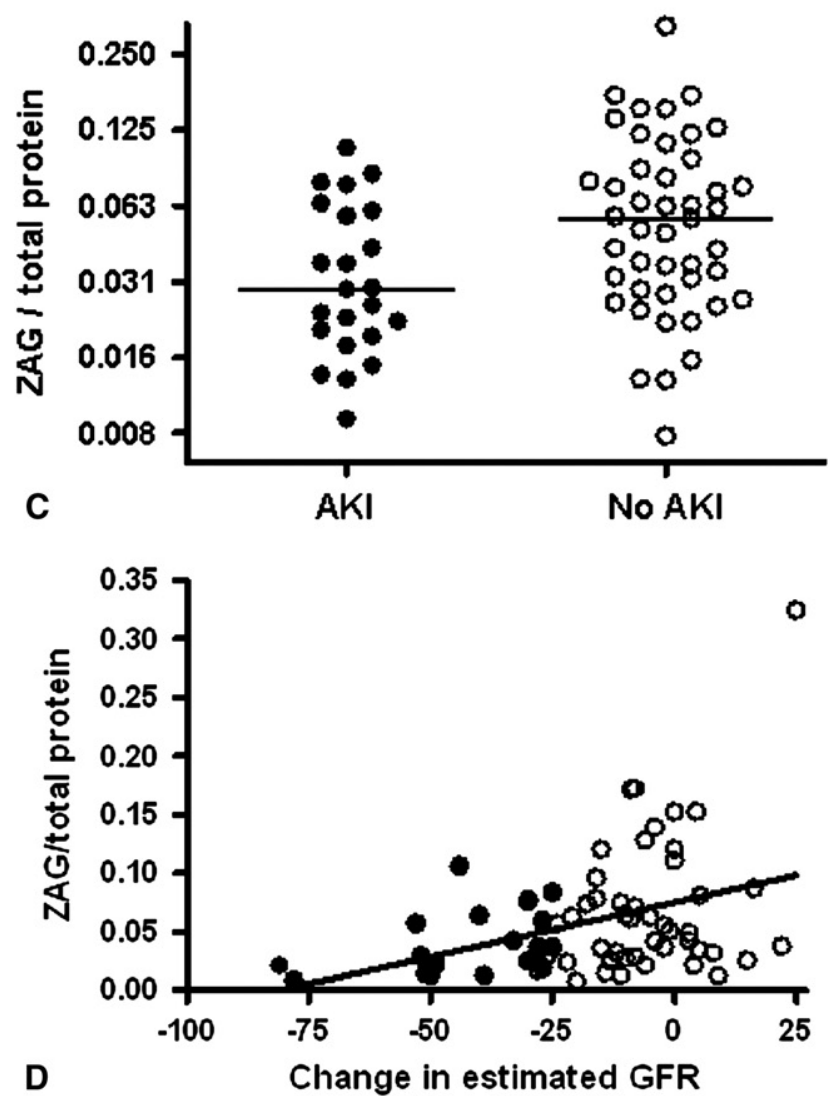

FIGURE 3. A, Representative Western blot of urinary ZAG in a patient with and without AKI. B, Correlation between Western blot and DIGE data of urinary ZAG in 6 patients with $(\bullet)$ and 6 patients without $(O)$ AKI. Spearman coefficient is $r=0.81, P=.01$. C, Urinary ZAG in 23 patients with $(\bigcirc)$ and 45 patients without $(\bigcirc)$ AKI given on a logarithmic scale. For differences between patients with and without AKI, see Results section. D, Correlation between CPB-induced changes in eGFR and urinary ZAG. Spearman coefficient between changes in eGFR and ZAG is $r=0.31$, $P<.01$. AKI, Acute kidney injury; $D I G E$, difference fluorescence gel electrophoresis; $G F R$, glomerular filtration rate; $Z A G$, zinc-alpha-2-glycoprotein. compared with patients without AKI. In diseases with increased epithelial cell proliferation such as prostatic cancer ${ }^{19}$ and polycystic kidney disease, ZAG was found to be downregulated. ZAG has recently been shown to inhibit cell proliferation in various cells, including renal tubular cells. ${ }^{20}$ Furthermore, in an ischemia-reperfusion model of AKI in mice, ZAG knockdown resulted in improved tubular cell proliferation after injury. ${ }^{20}$ Thus, it is conceivable that the differential expression of ZAG in patients with and without AKI is linked by an unknown mechanism with the AKI-associated tubular injury. The renal handling of ZAG is obscure. For instance, it seems to be unknown whether ZAG binds to cell surface receptors of renal cells and is taken up into the cells. Furthermore, whether urinary ZAG derives from glomerular plasma filtration or from tubular cells has not been elucidated. In addition, the analysis of ZAG is complicated by the fact that ZAG is induced by cortisol, a hormone increased after $\mathrm{CPB} .{ }^{21}$ The renal handling and renal tissue availability of glucocorticoids are strongly modulated in animals and humans with renal failure. Thus, the interplay between ZAG and AKI deserves future investigations.

Third, cardiac surgery with the aid of CPB induces a systemic inflammatory response syndrome (SIRS). ${ }^{22}$ Contact interactions of blood components with the artificial surface of the bypass circuit, ischemia-reperfusion injury, operative trauma, endotoxemia, blood loss, and transfusions are all possible causes of SIRS. The changes of albumin, leucinerich alpha-2-glycoprotein, mannan-binding lectin serine protease 2, and HSPG observed in the present study might be explained at least in part by SIRS.

For some proteins, such as gelsolin and carbonic anhydrase-1, we have no tentative explanation for the differential appearance in urine after CPB. Of interest, a decreased excretion of uromodulin has been described in various renal diseases, including acute tubular necrosis, lupus nephritis, and CPB-associated tubulopathy. Distal tubular dysfunction is a possible mechanism accounting for altered uromodulin handling.

This is the first study to analyze the urinary proteome of patients undergoing CPB with DIGE. Other methods have been applied for the urinary protein analysis in these patients. Nguyen and colleagues ${ }^{23}$ found 4 unidentified up-regulated proteins after CPB in patients with and without AKI by surface-enhanced laser desorption/ionization time-offlight mass spectrometry (SELDI-TOF-MS). Vanhoutte and colleagues ${ }^{2}$ compared postoperative urine samples of 20 unselected patients undergoing CPB with healthy controls by 2D gel electrophoresis and SELDI-TOF-MS. As in our work, RBP, gelsolin, ZAG, carbonic anhydrase, HSPG, and AMBP were up-regulated after CPB. In addition, Vanhouette and colleagues identified other differentially regulated proteins not seen by us and vice versa, a variance best explained by (1) the different study design including the same well-defined subjects pre- and 
postoperatively in the present study versus a cross-sectional analysis; (2) sample preparations; and (3) visualization techniques, that is, comparison of different gels in the study of Vanhouette and colleagues versus CyDye, an approach allowing different samples to be run on the same gel in the present study. ${ }^{9}$ Ho and colleagues ${ }^{6}$ recently analyzed hydrophobic proteins by SELDI-TOF-MS and found B2-microglobulin and hepcidin up-regulated after CPB. Hepcidin and another non-identified protein of a molecular mass of $2.43 \mathrm{kD}$ were up-regulated in patients without AKI.

The identification of urinary markers predicting renal injury early after an insult to the kidney has occurred is a tremendous undertaking. In a first step, we prospectively analyzed urine from a well-defined small number of patients before and after CPB by DIGE. By this approach, 3 differentially regulated proteins were identified in patients with AKI: up-regulation of a modified albumin and down-regulation of ZAG and a fragment of AMBP. ZAG levels determined by DIGE in the urine from the 12 patients were first confirmed by Western blot and then validated by ELISA in a second cross-sectional study of 68 patients after CPB. ZAG was significantly lower in AKI urine, and its excretion correlated with the change in eGFR. Down-regulation of ZAG was even more pronounced in severe AKI, such as injury and failure. Thus, ZAG might serve as a predictive marker in AKI after CPB. In recent years, several urinary biomarkers have been proposed for early detection of AKI after cardiac surgery, including neutrophil gelatinase-associated lipocalin (NGAL). An outstanding performance of NGAL in the early diagnosis of AKI has been reported in the homogenous population of pediatric patients undergoing cardiac surgery. In this population, an AUC value was reported to be as high as 0.98 . The corresponding values from non-pediatric patients were not that promising and ranged between 0.5 and $0.96 .^{24,25}$ It seems that the predictive value of NGAL depends on the time point of the assessments because the best discrimination between patients with and without AKI was 2 to 6 hours after cardiac surgery. Emerging experimental and clinical evidence indicates that NGAL protein expression is up-regulated in the distal nephron and that urinary secretion results in higher amounts of NGAL after tubular damage. The AUC of ZAG is is in the reported range of NGAL.

\section{Study Limitations}

First, the urinary proteome consists of a large number of different proteins, and 2 subsequent protein separation techniques are not feasible to separate all of them in a satisfactory manner. Furthermore, proteins within a given proteome are structurally diverse and present various physicochemical characteristics. Some of these proteins are alkaline or hydrophobic, are of poor solubility, or have different staining characteristics. Therefore, the present study in the urinary proteome of patients undergoing $\mathrm{CPB}$ revealed differential regulation of interesting proteins but could not detect all of them. Second, some of the differentially regulated spots could not be identified because of very low abundance. Because the sensitivity of CyDyes is higher than that of Coomassie dye, which is used for gel staining and spot picking, some spots cannot be identified even on a preparative gel. Third, antifibrinolytic therapy was different between groups $\mathrm{A}$ and $\mathrm{B}$ because of a change in local practice during the study period. Patients with and without AKI were given the same antifibrinolytic therapy within the groups. Down-regulation of ZAG was present in both groups in patients with AKI. Therefore, we do not believe the change in treatment biased the study results.

\section{CONCLUSIONS}

The present investigation demonstrates that DIGE allows unraveling new potentially interesting markers of CPB-associated AKI. After identification of such potential markers with the sensitive and specific but time-consuming and expensive DIGE technique applied in the present investigation, the candidate proteins can be considered for clinical practice after validation in larger cohorts by quantifying the proteins with ELISA in a fast and inexpensive manner. Two main groups of differentially regulated proteins were identified: inflammation-associated or candidates of megalin-mediated endocytosis. ZAG is a potential marker for early prediction of AKI after CPB.

The authors thank Yolanda Auchli and Mike Scott from the Functional Genomics Center Zürich for MS analysis and technical support.

\section{References}

1. Loef BG, Epema AH, Smilde TD, Henning RH, Ebels T, Navis G, et al. Immediate postoperative renal function deterioration in cardiac surgical patients predicts in-hospital mortality and long-term survival. J Am Soc Nephrol. 2005;16: 195-200.

2. Vanhoutte KJ, Laarakkers C, Marchiori E, Pickkers P, Wetzels JF, Willems JL, et al. Biomarker discovery with SELDI-TOF MS in human urine associated with early renal injury: evaluation with computational analytical tools. Nephrol Dial Transplant. 2007;22:2932-43.

3. Blaikley J, Sutton P, Walter M, Lapsley M, Nordan A, Pugsley W, et al. Tubular proteinuria and enzymuria following open heart surgery. Intensive Care Med. 2003;29:1364-7

4. Delanty N, Reilly MP, Pratico D, Lawson JA, McCarthy JF, Wood AE, et al. 8-epi PGF2 alpha generation during coronary reperfusion. A potential quantitative marker of oxidant stress in vivo. Circulation. 1997;95:2492-9.

5. Frey FJ, Frey BM, Koegel R, Hodler J, Wegmueller E. Selectivity as a clue to diagnosis of postural proteinuria. Lancet. 1979;1:343-5.

6. Ho J, Lucy M, Krokhin O, Hayglass K, Pascoe E, Darroch G, et al. Mass spectrometry-based proteomic analysis of urine in acute kidney injury following cardiopulmonary bypass: a nested case-control study. Am J Kidney Dis. 2009;53: 584-95.

7. Gorg A, Weiss W, Dunn MJ. Current two-dimensional electrophoresis technology for proteomics. Proteomics. 2004;4:3665-85

8. Pilop C, Aregger F, Gorman RC, Brunisholz R, Gerrits B, Schaffner T, et al. Proteomic analysis in aortic media of patients with Marfan syndrome reveals in creased activity of calpain 2 in aortic aneurysms. Circulation. 2009;120:983-91.

9. Unlu M, Morgan ME, Minden JS. Difference gel electrophoresis: a single gel method for detecting changes in protein extracts. Electrophoresis. 1997;18: 2071-7. 
10. Alban A, David SO, Bjorkesten L, Andersson C, Sloge E, Lewis S, et al. A novel experimental design for comparative two-dimensional gel analysis: two-dimensional difference gel electrophoresis incorporating a pooled internal standard. Proteomics. 2003;3:36-44.

11. Thongboonkerd V. Practical points in urinary proteomics. J Proteome Res. 2007; 6:3881-90.

12. Bensadoun A, Weinstein D. Assay of proteins in the presence of interfering materials. Anal Biochem. 1976;70:241-50.

13. Bradford MM. A rapid and sensitive method for the quantitation of microgram quantities of protein utilizing the principle of protein-dy binding. Anal Biochem. 1976;72:248-54.

14. Bellomo R, Ronco C, Kellum JA, Mehta RL, Palevsky P. Acute Dialysis Quality Initiative workgroup. Acute renal failure-definition, outcome measures, animal models, fluid therapy and information technology needs: the second international consensus conference of the acute dialysis quality initiative (ADQI) group. Crit Care. 2004;8:R204-12.

15. Bernard AM, Vyskocil AA, Mahieu P, Lauwerys RR. Assessment of urinary retinolbinding protein as an index of proximal tubular injury. Clin Chem. 1987;33:775-9.

16. Herget-Rosenthal S, Poppen D, Husing J, Marggraf G, Pietruck F, Jakob HG, et al. Prognostic value of tubular proteinuria and enzymuria in nonoliguric acute tubular necrosis. Clin Chem. 2004;50:552-8.

17. Verroust PJ, Birn H, Nielsen R, Kozyraki R, Christensen EI. The tandem endocytic receptors megalin and cubilin are important proteins in renal pathology. Kidney Int. 2002;62:745-56.
18. Lebeau C, Debelle FD, Arlt VM, Pozdzik A, De Prez EG, Phillips DH, et al. Early proximal tubule injury in experimental aristolochic acid nephropathy: functional and histological studies. Nephrol Dial Transplant. 2005;20:2321-32.

19. Descazeaud A, de la Taille A, Allory Y, Faucon H, Salomon L, Bismar T, et al. Characterization of ZAG protein expression in prostate cancer using a semi-automated microscope system. Prostate. 2006;66:1037-43.

20. Schmitt R, Marlier A, Cantley LG. Zag expression during aging suppresses proliferation after kidney injury. J Am Soc Nephrol. 2008;19:2375-83.

21. Kono K, Philbin DM, Coggins CH, Slater EE, Triantafillou A, Levine FH, et al. Adrenocortical hormone levels during cardiopulmonary bypass with and without pulsatile flow. J Thorac Cardiovasc Surg. 1983;85:129-33.

22. Formica F, Broccolo F, Martino A, Sciucchetti J, Giordano V, Avalli L, et al. Myocardial revascularization with miniaturized extracorporeal circulation versus off pump: evaluation of systemic and myocardial inflammatory response in a prospective randomized study. J Thoracic Cardiovasc Surg. 2009; 137:1206-12.

23. Nguyen MT, Ross GF, Dent CL, Devarajan P. Early prediction of acute renal injury using urinary proteomics. Am J Nephrol. 2005;25:318-26.

24. Tuladhur SM, Püntmann VO, Soni M, Punjabi PP, Bogle RG. Rapid detection of acute kidney injury by plasma and urinary neutrophil gelatinase-associated lipocalin after cardiopulmonary bypass. J Cardiovasc Pharmacol. 2009;53:261-6.

25. Liangos O, Tighiouart H, Perianayagam MC, Kolyada A, Han WK, Wald R, et al. Comparative analysis of urinary biomarkers for early detection of acute kidney injury following cardiopulmonary bypass. Biomarkers. 2009;14:423-31. 